\title{
Prevention of renal ischemia and reperfusion injury by penehyclidine hydrochloride through autophagy activation
}

\author{
YUQING KANG ${ }^{1}$, YUEBING $\mathrm{LI}^{2}$, HENG WEN ${ }^{2}$, JUNFENG ZHU ${ }^{1}$, JIANGBO ZHENG ${ }^{1}$ and ZHAOMING FENG ${ }^{1}$ \\ ${ }^{1}$ Department of Anesthesiology, Jinshan Branch Hospital of Shanghai Sixth People's Hospital, Shanghai 201599; \\ ${ }^{2}$ Department of Anesthesiology, The Second Affiliated Hospital of Zhejiang Chinese Medical University, \\ Hangzhou, Zhejiang 310005, P.R. China
}

Received June 11, 2019; Accepted November 29, 2019

DOI: $10.3892 / \mathrm{mmr} .2020 .11024$

\begin{abstract}
Penehyclidine hydrochloride (PHC) suppresses renal ischemia and reperfusion (I/R) injury (IRI); however, the underlying mechanism of action that achieves this function remains largely unknown. The present study aimed to investigate the potential role of autophagy in PHC-induced suppression of renal IRI, as well as the involvement of cell proliferation and apoptosis. A rat IRI model and a cellular hypoxia/oxygenation (H/R) model were established; PHC, 3-methyladenine (3-MA) and rapamycin (Rapa) were administered to the IRI model rats prior to I/R induction and to $\mathrm{H} / \mathrm{R}$ cells following reperfusion. Serum creatinine was measured using a biochemistry analyzer, whereas aspartate aminotransferase (ASAT) and alanine aminotransferase (ALAT) expression levels were detected using ELISA kits. Renal tissue injury was evaluated by histological examination. In addition, microtubule-associated protein light chain 3B (LC3B) expression, autophagosome formation, cell proliferation and apoptosis were detected in the cellular $\mathrm{H} / \mathrm{R}$ model. The results demonstrated that I/R induced renal injury in IRI model rats, upregulated serum creatinine, ALAT and ASAT expression levels, and increased autophagic processes. In contrast, pretreatment with $\mathrm{PHC}$ or Rapa significantly prevented these I/R-induced changes, whereas the administration of 3-MA enhanced I/R-induced injuries through suppressing autophagy. PHC and Rapa increased LC3B and Beclin-1 expression levels, but decreased sequestome 1 (p62) expression in the cellular H/R model, whereas 3-MA prevented these PHC-induced changes. PHC and Rapa promoted proliferation and autophagy in the cellular H/R model; these effects were accompanied by increased expression levels of LC3B and Beclin-1, and reduced
\end{abstract}

Correspondence to: Dr Junfeng Zhu, Department of Anesthesiology, Jinshan Branch Hospital of Shanghai Sixth People's Hospital, 147 Health Road, Zhujing, Jinshan, Shanghai 201599, P.R. China

E-mail: zysmz@126.com; wbxkang201809@163.com

Key words: penehyclidine hydrochloride, renal ischemia and reperfusion injury, autophagy, proliferation, apoptosis p62 expression levels, whereas these levels were inhibited by 3-MA. Furthermore, PHC and Rapa inhibited apoptosis in the cellular H/R model through increasing Bcl-2 expression levels, and suppressing Bax and caspase-3 expression levels; the opposite effect was induced by 3 -MA. In conclusion, PHC suppressed renal IRI through the induction of autophagy, which in turn promoted proliferation and suppressed apoptosis in renal cells.

\section{Introduction}

Ischemia/reperfusion injury (IRI) is caused by restricted blood flow to organs and the subsequent restoration of blood flow and oxygen; it usually occurs following sepsis, infarction or organ transplantation, and damages tissues through triggering inflammatory cascades involving cytokines, chemokines and reactive oxygen species (ROS) $(1,2)$. IRI within the kidneys is a major factor contributing to acute kidney injury, which is a pathological syndrome characterized by rapid progressive renal dysfunction and a high rate of mortality $(1,3,4)$. Pathophysiological investigations have revealed that IRI in kidney tissue is closely associated with complex interactions among various molecules and pathogenic events, including cytokines, inflammatory factors, adhesion molecules, neutrophil activation, and ROS production and release (5-7). Moreover, the aberrant apoptosis of renal cells, such as tubular cells, due to elevated oxidative stress and enhanced mitochondrial pathway activity has been demonstrated to occur during the pathogenesis of renal IRI (8). Several therapeutic reagents and methods that inhibit renal cell apoptosis have demonstrated promising potential as novel treatments for renal IRI in animal models, which require further validation; these include hyperbaric oxygen therapy, hydrogen-rich saline and hypothermic machine perfusion (9-11). Investigating the molecular mechanisms that underlie the pharmacological effects of anti-IRI drugs may enable the development and clinical application of novel therapies for IRI.

Penehyclidine hydrochloride (PHC) is a novel selective anti-cholinergic drug derived from scopolamine, which demonstrates various pharmacological effects, including anti-muscarinic, anti-inflammatory, anti-oxidative stress, anti-apoptotic and anti-nicotinic activity (12). PHC has 
previously been used in the clinic to treat pulmonary dysfunction associated with chronic obstructive pulmonary disease, and organophosphate and soman poisoning, through its regulation of the microcirculation, lysosome release and lipid peroxidation (12). In addition, PHC has been reported to protect against lipopolysaccharide-, and cecal ligation and puncture-induced acute lung injury through regulating the mitogen-activated protein kinase (MAPK) and NF- $\kappa \mathrm{B}$ signaling pathways $(13,14)$. PHC has demonstrated promise in preventing cardiopulmonary bypass-induced cardiopulmonary liver damage, limb ischemia/reperfusion (I/R)-associated small intestinal damage and middle cerebral artery occlusion-induced cerebral IRI $(15,16)$. Notably, PHC significantly suppressed the histological damage and dysfunction of renal tissue induced by $\mathrm{I} / \mathrm{R}$, and substantially altered the activity of MAPK, caspase -3 and NF- $\kappa B$ proteins, in a rat model (17). Regulation of the apoptosis-associated protein caspase- 3 by PHC suggested that PHC may be able to modulate apoptosis during I/R-induced damage to renal tissues; however, the underlying mechanisms, particularly the cellular and molecular events that may enable PHC-induced inhibition of renal IRI remain to be investigated.

Autophagy is the cellular process of disassembling unnecessary and dysfunctional components, in order to facilitate lysosome-mediated degradation and the recycling of these useless cellular components (18). In certain pathogenic processes, autophagy serves as an adaptive response to adverse stress and it is a method of maintaining cellular energy that is required to promote cell survival and inhibit disease progression $(19,20)$. For example, the induction of autophagy has been demonstrated to be an important mechanism for protecting against IRI in liver tissue and it was also involved in inhibiting ischemic liver damage produced by cisplatin (21). The activation of autophagy is linked to various pharmacological effects, such as the inhibition of d-galactosamine-induced acute liver injury by schisandrin A (22) and the suppression of hepatic IRI by hydrogen sulfide (23). Notably, autophagy was revealed to be important for kidney tubule maintenance and it contributed to the mechanism that protects against IRI in kidney tissues $(24,25)$. The target of rapamycin (TOR) is a highly conserved serine/threonine protein kinase that acts as a central sensor for growth factors, nutrient signals and energy status. For example, TOR expression can be effectively promoted in response to nutrient signals, which finally modulates cell growth by regulation of nutrient uptake, protein synthesis and metabolic processes (26). In addition, the mammalian (m)TOR signaling pathway serves as a master regulator of autophagy (27). It has been demonstrated that Beclin-1, sequestosome 1 (p62) and microtubule-associated protein light chain $3 \mathrm{~B}$ (LC3B) are key proteins involved in the stepwise process of autophagy $(28,29)$. LC3B is a central player in the autophagy pathway, which is responsible for autophagy substrate selection and autophagosome biogenesis (30); the LC3B-II/I ratio is widely used as a marker of autophagy, as LC3B-I is converted to LC3B-II during autophagy (31). Beclin-1, as the mammalian orthologue of yeast autophagy-related gene (ATG)6, promotes autophagy and programmed cell survival through interacting with various cofactors, such as ATG14 and survivin proteins (32). p62 is associated with both cell apoptosis and autophagy processes (33); however, it is unclear whether autophagy is a mechanism induced by PHC to inhibit renal IRI and if so, the possible signaling pathway that occurs remains undiscovered.

The present study aimed to analyze the effects of PHC treatment on renal tissue damage, cell apoptosis and autophagy in a rat IRI model and a cellular hypoxia/oxygenation (H/R) model to determine the molecular mechanisms underlying PHC-induced renal IRI inhibition. The findings of the present study provided novel insights into the tissue injury-suppressive roles of PHC.

\section{Materials and methods}

Animal studies. All procedures in this study were approved by the Ethics Committee for Experimental Animals of the Jinshan Branch Hospital of Shanghai Sixth People's Hospital (Shanghai, China) and were carried out in strict accordance with the Guide for the Care and Use of Laboratory Animals, 8th edition (National Institutes of Health) (34). A total of 50 Sprague-Dawley rats (age, 6 weeks; male; weight, 180-200 g) were purchased from the Laboratory Animal Center of the Jinshan Branch Hospital of Shanghai Sixth People's Hospital. The rats were housed in a room maintained at $27^{\circ} \mathrm{C}, 50 \%$ relative humidity, under a 12-h light/dark cycle, with rodent chow and tap water available ad libitum. The rats were randomly assigned to five groups (10 rats/group): i) Sham group, which was subjected to the same surgical operation as the I/R group without occlusion of the renal artery; ii) I/R group; iii) I/R + PHC group; iv) I/R + PHC + 3-methyladenine (3-MA; an autophagy inhibitor) group; and, v) I/R + Rapamycin (Rapa; a common autophagy inducer) group.

PHC (0.45 mg/kg; Chengdu List Pharmaceutical, Co., Ltd.), 3-MA (0.5 mg/100 g; cat. no. S2767; Selleck Chemicals) and Rapa (1 mg/100 g; cat. no. AY22989; MedChemExpress) were intravenously administered to rats $30 \mathrm{~min}$ prior to I/R induction, as previously described (17). Briefly, the rats were anesthetized by intraperitoneal administration of sodium pentobarbital $(50 \mathrm{mg} / \mathrm{kg})$, and their neck and abdomen were shaved and washed with povidone iodine. The right external jugular vein was isolated and catheterized with a catheter secured with a sterile suture and connected to a T-branch pipe for administration of PHC, 3-MA and Rapa.

For induction of I RI, the rats were subjected to removal of the right kidney out of the abdominal cavity, artery clamping and reperfusion after receiving the specified drug treatments, as previously described (35). Briefly, the rat kidneys were exposed and removed by a midline laparotomy, followed by occlusion of the left renal artery using a microvascular clamp. The left renal artery occlusion lasted for $40 \mathrm{~min}$ and removing the clamp induced reperfusion.

After reperfusion for $6 \mathrm{~h}$, the rats were sacrificed and the kidneys were collected for subsequent evaluation and analysis. Rat blood samples $(2 \mathrm{ml})$ were collected from the inferior vena cava, centrifuged $(3,000 \mathrm{x} \mathrm{g} ; 18 \mathrm{~min})$ at $4^{\circ} \mathrm{C}$ to remove the plasma, and serum was stored for serum creatinine $(\mathrm{SCr})$ measurements performed with a Roche Cobas C111 analyzer (Roche Diagnostics). For purposes of quantification and statistical analysis, the $\mathrm{SCr}$ measurements in each group were repeated $\geq 3$ times. 
ELISA. To evaluate the liver injuries induced by renal IRI, serum from each group was analyzed for serum aspartate aminotransferase (ASAT; cat. no. E-EL-R0076; Elabscience Biotechnology Co., Ltd.) and alanine aminotransferase (ALAT) expression levels using commercial ELISA kits (cat. no. ZK-R4034; Shenzhen Ziker Biological Technology Co., Ltd.), according to the manufacturer's instructions.

Histological analysis. Histological damage in rat renal tubules was evaluated by hematoxylin \& eosin (H\&E) staining, Masson's trichrome staining and Periodic acid-Schiff (PAS) staining, as previously described (36). The rat kidney tissues were fixed in $4 \%$ paraformaldehyde for $24 \mathrm{~h}$ at room temperature, embedded in paraffin and cut into thin sections $(4-\mu \mathrm{m})$. $\mathrm{H} \& \mathrm{E}$ staining was performed according to a standard protocol; briefly, sections of rat kidney tissue were mounted on slides and stained with $2 \%$ hematoxylin at room temperature for $5 \mathrm{~min}$, followed by staining with $0.5 \%$ eosin at room temperature for $2 \mathrm{~min}$. For Masson's trichrome staining, sections of rat renal tissue were first stained with Ponceau $\mathrm{S}$ acid fuchsin for $10 \mathrm{~min}$ at room temperature; after which, they were incubated with molybdophosphoric acid for $3 \mathrm{~min}$ at room temperature, and finally stained with $0.5 \%$ aniline blue for $5 \mathrm{~min}$. For detection of glycogen by PAS staining, the mounted sections were oxidized in 0.5 periodic acid solution for $5 \mathrm{~min}$, incubated in Schiff reagent for $12 \mathrm{~min}$, and then counterstained with hematoxylin for $1 \mathrm{~min}$ at room temperature. Histological images were captured using a light microscope (all magnifications, $\mathrm{x} 200$ and $\mathrm{x} 400$ ).

Cell culture and reagents. The human proximal tubular human kidney 2 (HK-2) cell line (\#CRL-2190) was obtained from the American Type Culture Collection and used to establish a cellular $\mathrm{H} / \mathrm{R}$ model in vitro. The cells were cultured in DMEM (Gibco; Thermo Fisher Scientific, Inc.), supplemented with $0.05 \mathrm{mg} / \mathrm{ml}$ bovine pituitary extract (cat. no. abs9119; AbSin) and 10\% FBS (Gibco; Thermo Fisher Scientific, Inc.), and maintained in a humidified atmosphere at $37^{\circ} \mathrm{C}$ containing $5 \% \mathrm{CO}_{2}$. To establish the cellular $\mathrm{H} / \mathrm{R}$ model, $\mathrm{HK}-2$ cells were cultured in low-glucose DMEM without FBS under hypoxic conditions (1\% oxygen) for $4 \mathrm{~h}$, and subsequently cultured under normal conditions for $24 \mathrm{~h}$, as previously described (37). Subsequently, HK-2 cells were treated with $0.1 \mu \mathrm{M}$ PHC, $4 \mathrm{mM}$ 3 -MA or $2 \mu \mathrm{M}$ Rapa at room temperature for $2 \mathrm{~h}$, and analyzed for their proliferative, apoptotic and autophagic ability.

Immunofluorescence analysis. For analysis of the protein expression levels in renal tissue or HK-2 cells, the paraffin-embedded tissue sections $(4 \mu \mathrm{m})$ or cells $\left(1 \times 10^{6} / \mathrm{ml}\right)$ were fixed in $4 \%$ formaldehyde solution at room temperature for $15 \mathrm{~min}$, rinsed three times with PBS for 5 min and incubated with the BLOT-QuickBlocker blocking buffer (cat. no. C006011; Sangon Biotech Co., Ltd.) for $60 \mathrm{~min}$ at room temperature. The tissues and cells were subsequently incubated with anti-LC3B primary antibodies (cat. no. 3868; 1:200; Cell Signaling Technology, Inc.) overnight at $4^{\circ} \mathrm{C}$. Following the primary antibody incubation, the sections or cells were washed three times with PBS ( $5 \mathrm{~min} /$ wash), incubated with fluorescence-labeled secondary antibodies (cat. no. 4414; 1:500; Cell Signaling Technology, Inc.) for $2 \mathrm{~h}$ in the dark, washed with PBS and subsequently mounted with Prolong ${ }^{\circledR}$ Gold Antifade Reagent (cat. no. 9071; Cell Signaling Technology, Inc.). The protein expression levels in rat tissues or cells were determined using a fluorescence microscope (magnification, x100).

Western blotting. Total protein was extracted from rat kidney tissues or HK-2 cells using $0.5 \mathrm{ml}$ lysis buffer (cat. no. C500035; Sangon Biotech Co., Ltd.) containing 1\% phenylmethylsulfonyl fluoride and a proteinase inhibitor cocktail (Sigma-Aldrich; Merck KGaA). Following centrifugation (14,000 x g; $10 \mathrm{~min}$; $4^{\circ} \mathrm{C}$ ), the supernatant was collected and total protein was quantified using a bicinchoninic acid assay kit (cat. no. 23227; Pierce; Thermo Fisher Scientific, Inc.). Following quantification, $\sim 30 \mu \mathrm{g}$ protein was boiled at $100^{\circ} \mathrm{C}$ for $5 \mathrm{~min}$ and separated by SDS-PAGE on $10 \%$ gels. The separated proteins were subsequently transferred onto PVDF membranes (EMD Millipore) and blocked for $2 \mathrm{~h}$ at room temperature with $5 \%$ non-fat milk solution. The membranes were incubated with the following primary antibodies (Abcam) diluted in TBS-Tween $20(0.5 \%)$ for $2 \mathrm{~h}$ : Anti-Beclin-1 (cat. no. ab62557; 1:2,000), anti-p62 (cat. no. ab56416; 1: 2,500), anti-LC3B (cat. no. ab63817; 1:2,000), anti-Bcl-2 (cat. no. ab196495; 1:2,000), anti-Bax (cat. no. ab53154; 1:3,000), anti-cleaved caspase-3 (cat. no. ab2302; $1: 2,000)$ and anti- $\beta$-actin (cat. no. ab8227; 1:2,500). Following the primary antibody incubation, the membranes were washed three times with PBS at room temperature and subsequently incubated with anti-rabbit IgG (cat. no. ab205718; 1:2,000; Abcam) or anti-mouse IgG (cat. no. ab205719; 1:2,000; Abcam) secondary antibodies for $1-2 \mathrm{~h}$ at room temperature. Protein bands were visualized using the Pierce ${ }^{\mathrm{TM}}$ ECL Western Blotting Substrate (Pierce; Thermo Fishier Scientific, Inc.). Protein expression was semi-quantified using Image-Pro Plus version 6.0 software (Media Cybernetics, Inc.) with $\beta$-actin as the loading control.

Cell counting kit-8 (CCK-8) assay. Following treatment as specified, the proliferation of HK-2 cells was determined using a CCK-8 assay (cat. no. C0038; Beyotime Institute of Biotechnology), according to the manufacturer's protocol. Briefly, HK-2 cells $\left(1 \times 10^{6} / \mathrm{ml}\right)$ were cultured in 96-well plates and incubated with CCK- 8 solution for $24 \mathrm{~h}$ at $37^{\circ} \mathrm{C}$ under normal cell culture conditions. Cell proliferation was quantified by measuring the absorbance of each well at $450 \mathrm{~nm}$ using a microplate reader. Each CCK-8 assay was repeated $\geq 3$ times.

Transmission electron microscopy (TEM). Autophagic processes in rat renal cells were evaluated by TEM, as previously described (38). Briefly, sections of renal tissue (4 $\mu \mathrm{m}$ ) were fixed with $10 \%$ neutral buffered formalin (cat. no. G2240; Beijing Solarbio Science \& Technology Co., Ltd.) at room temperature for $2 \mathrm{~h}$, embedded with LR white resin (cat. no. 62661; Sigma-Aldrich; Merck KGaA) overnight at $55^{\circ} \mathrm{C}$, mounted on slides and stained with $0.5 \%$ toluidine blue at room temperature for $20 \mathrm{~min}$. Slides were subsequently rinsed with TBS solution and blocked with 5\% BSA solution (cat. no. ST023; Beyotime Institute of Biotechnology) at room temperature for $30 \mathrm{~min}$. The sections were washed with TBS solution and incubated with diluted primary antibodies (cat. no. 3868; 1:200; Cell Signaling Technology, Inc.) for $1 \mathrm{~h}$ at 
room temperature. Following the primary antibody incubation, sections were washed with PBS and incubated with a gold-conjugated secondary antibody (cat. no. GA1004; Boster Biological Technology) for $1 \mathrm{~h}$ at room temperature. Autophagy in renal cells was analyzed using a transmission electron microscope (magnification, x100).

Apoptosis analysis. The apoptotic rates of HK-2 cells after respective treatments were determined by Hoechst 33258 staining and flow cytometry, following fixation with $4 \%$ paraformaldehyde for $10 \mathrm{~min}$ at room temperature. For apoptosis evaluation by Hoechst staining, HK-2 cells $\left(2 \times 10^{6} /\right.$ cell) were stained with Hoechst $33258(5 \mu \mathrm{g} / \mathrm{ml}$; Sigma-Aldrich; Merck KGaA) for $20 \mathrm{~min}$ in the dark at room temperature, washed three times with PBS (5 min each) and analyzed using a fluorescence microscope (Canon, Inc.; magnification, $\mathrm{x} 100)$. For flow cytometric analysis of apoptosis, HK-2 cells (2x10\% cell) were stained with $5 \mu \mathrm{l}$ Annexin V-FITC and $5 \mu \mathrm{l}$ propidium iodide for $5 \mathrm{~min}$ in the dark at room temperature using the Annexin V-FITC Apoptosis Staining Detection kit (cat. no. ab14085; Abcam). Cell apoptosis was finally detected using a BD Accuri C6 flow cytometry (BD Biosciences) and analyzed using FlowJo 7.6.1 software (FlowJo, LLC). Each apoptosis assay was repeated $\geq 3$ times.

Statistical analysis. All data, based on at least three biological repeats, were analyzed using PASW Statistics version 18.0 software (SPSS Inc.) and data are presented as the mean \pm SD. Statistical differences between groups were compared using one-way ANOVA followed by Tukey's post hoc test for multiple comparisons. $\mathrm{P}<0.05$ was considered to indicate a statistically significant difference.

\section{Results}

PHC suppresses renal injury in the rat IRI model through autophagy activation. Sprague-Dawley rats subjected to $\mathrm{I} / \mathrm{R}$ were used as an animal model for studying the effects of PHC on renal injury. SCr levels were significantly increased in the I/R group compared with the sham group (Fig. 1); PHC treatment significantly decreased this increase in $\mathrm{SCr}$ levels observed in the I/R group (Fig. 1). Notably, treatment with the autophagy inhibitor 3-MA (I/R + PHC +3 -MA group) induced a significant increase in SCr levels compared with the I/R + PHC group, suggesting a potential role for autophagy as a mechanism of action underlying PHC-induced renal IRI inhibition (Fig. 1). The involvement of autophagy in PHC-induced renal IRI suppression was further demonstrated through the significantly decreased SCr levels observed in the I/R + Rapa group compared with the I/R + PHC group (Fig. 1).

Similar changes were observed in the liver enzymes ALAT and ASAT (Fig. S1), the expression levels of serum ALAT and ASAT in the I/R group were significantly increased compared with the sham group, whereas pretreatment with PHC or Rapa (I/R + PHC and I/R + Rapa groups, respectively) significantly decreased IRI-induced increases in serum ALAT and ASAT levels compared with the I/R group. However, treatment with 3-MA (I/R + PHC + 3-MA group) significantly attenuated the PHC-induced inhibition of ALAT and ASAT observed in the

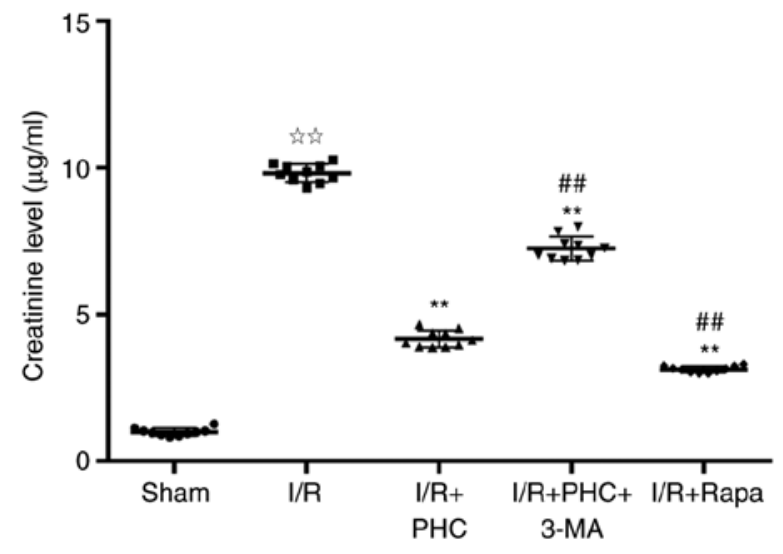

Figure 1. Serum creatinine levels in IR injury model rats following treatment with PHC, 3-MA or Rapa. Serum creatinine levels were detected using ELISA in the sham, I/R, I/R + PHC, I/R + PHC + 3-MA and I/R + Rapa groups. ${ }^{\text {"रे }} \mathrm{P}<0.01$ vs. sham group; ${ }^{* *} \mathrm{P}<0.01$ vs. I/R group; ${ }^{\# \#} \mathrm{P}<0.01$ vs. I/R+PHC group. 3-MA, 3-methyladenine; I/R, ischemia/reperfusion; PHC, penehyclidine hydrochloride; Rapa, rapamycin.

I/R + PHC group (Fig. S1). These data indicated that remote liver injury had occurred following renal IRI and suggested that PHC or Rapa may prevent such liver injury.

H\&E staining of rat kidney tissues demonstrated markedly aberrant morphological alterations in the I/R group, including swollen renal tubular epithelial cells, clear necrosis and cytolysis, and renal interstitial congestion (Fig. 2A). The damage to renal tissues in the I/R group was suppressed by PHC treatment, promoted to a certain extent by 3-MA and inhibited by Rapa (Fig. 2A). Masson's trichrome staining of the collagenous fibers demonstrated inhibition of renal tubular damage by PHC treatment in the I/R + PHC group; conversely, the renal tubular damage was exaggerated by 3-MA treatment in the I/R + PHC group but alleviated by rapamycin treatment in the $I / R+$ Rapa group (Fig. 2B). PAS staining revealed mesangial stromal hyperplasia and basement membrane thickening in renal tissues the I/R group; these pathological changes were inhibited by PHC treatment (I/R + PHC group), promoted by combined 3-MA and PHC treatment (I/R + PHC + 3-MA group), and suppressed by Rapa treatment (I/R + Rapa group) (Fig. 2C). The effects of the autophagy inhibitor 3-MA and autophagy inducer Rapa on renal tubular damage in an rat model of IRI suggested that autophagic processes may serve important roles in renal IRI.

PHC promotes autophagy processes during IRI inhibition in vivo. To further investigate the role of autophagy in PHC-induced IRI inhibition, the expression of autophagy markers in the renal tissues of IRI model rats were investigated. Expression levels of the autophagy marker LC3B were markedly increased in the $\mathrm{I} / \mathrm{R}+\mathrm{PHC}$ group compared with the I/R group (Fig. 3A); however, 3-MA treatment (I/R + $\mathrm{PHC}+3-\mathrm{MA}$ group) decreased LC3B expression levels in the renal tissues of rats, despite receiving PHC treatment. In contrast, the I/R + Rapa group demonstrated markedly increased expression levels of LC3B, in comparison with the I/R group (Fig. 3A). In addition, western blotting demonstrated that the protein expression levels of Beclin-1 were significantly increased in the I/R + PHC group compared 
A
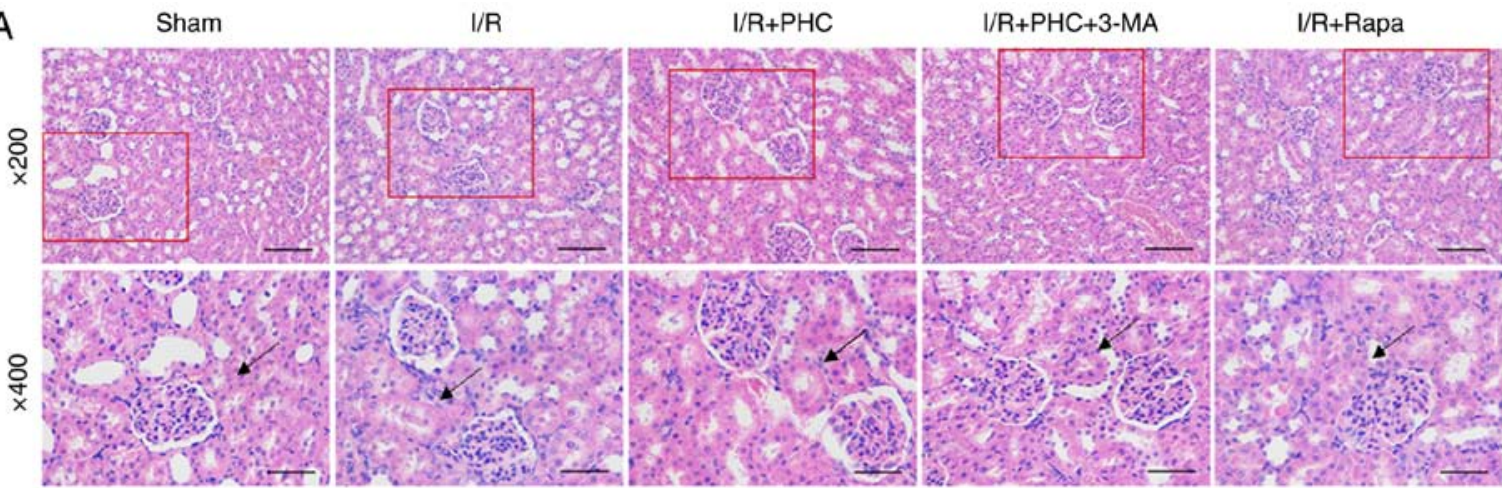

B
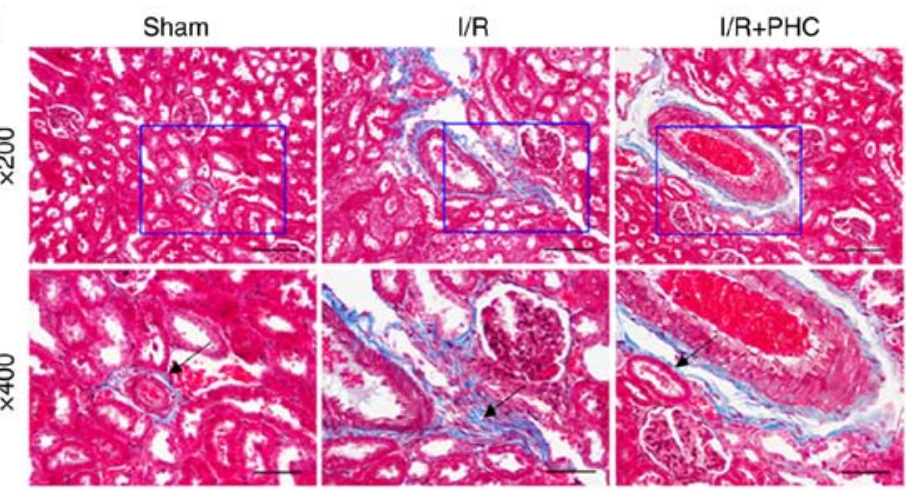

I/R+PHC+3-MA

I/R+Rapa

C

I/R

$\mathrm{I} / \mathrm{R}+\mathrm{PHC}$
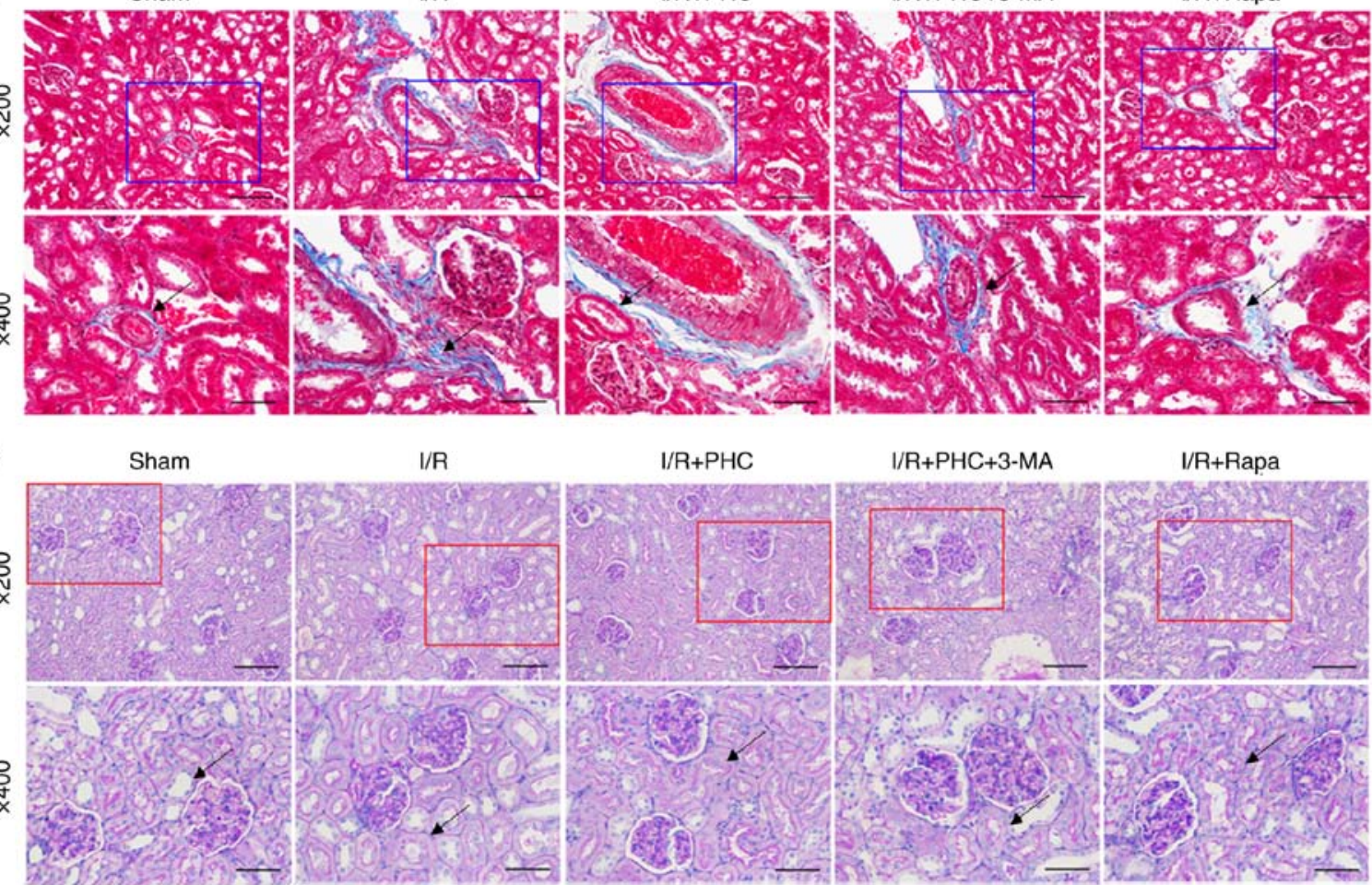

I/R+PHC+3-MA

l/R+Rapa

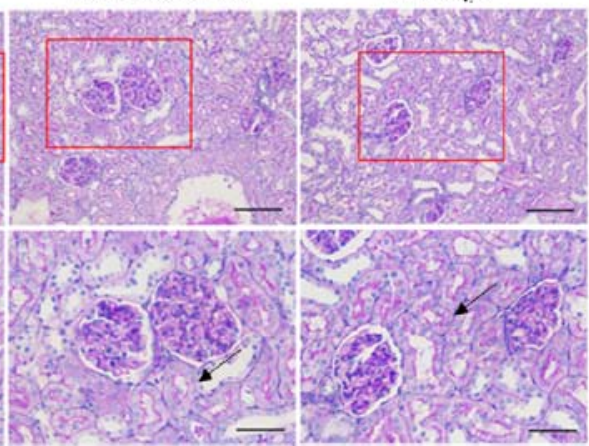

Figure 2. Modulation of renal IRI by PHC, Rapa and a combination of 3-MA and PHC. (A) Hematoxylin \& eosin staining of renal tubular injury in the IRI model rats following treatment with PHC, 3-MA or Rapa (magnifications, x200 or x400). (B) Masson's trichrome staining of collagenous fibers in the IRI model rats following treatment with PHC, 3-MA or Rapa (magnifications, $\mathrm{x} 200$ or x400). (C) Periodic acid-Schiff staining of mesangial stromal and basement membrane thickening in renal tissues of the IRI model rats following treatment with PHC, 3-MA or Rapa (magnifications, x200 or x400). Pathogenic alterations are indicated by black arrows. All scale bars, 50 or $100 \mu \mathrm{m}$. 3-MA, 3-methyladenine; I/R, ischemia/reperfusion; IRI, I/R injury; PHC, penehyclidine hydrochloride; Rapa, rapamycin.

with the I/R group; however, expression levels of Beclin-1 were significantly decreased in the I/R + PHC + 3-MA group compared with the I/R + PHC group, whereas the I/R + Rapa group demonstrated significantly increased Beclin-1 expression levels compared with the I/R group rats (Fig. 3B and C). Similar alterations in LC3BII expression in rat renal tissues were also validated by western blotting, whereas LC3BI expression exhibited no significant changes between these groups (Fig. 3B and C). The expression levels of p62 in the renal tissues of all rat groups exhibited inverse alterations compared with the expression levels of Beclin-1 and LC3B (Fig. 3B and C). These alterations in the protein expression levels of LC3B, Beclin-1 and p62 expression suggested that PHC treatment may activate autophagic processes during the inhibition of renal IRI.
Autophagy promotes PHC-induced proliferation in the in vitro H/R model. To provide evidence of the involvement of autophagy PHC-induced IRI inhibition, a cellular H/R model was established using the human proximal tubular HK-2 cell line. The proliferative rates of HK-2 cells following H/R (H/R group) were decreased compared with the control group (Fig. 4A); this proliferative rate was increased by PHC treatment (H/R + PHC group), whereas treatment with 3-MA (H/R $+\mathrm{PHC}+3$-MA group) markedly decreased the proliferation of HK-2 cells compared with all other groups (Fig. 4A). Notably, Rapa treatment increased the proliferative rate of $H / R$ cells (Fig. 4A).

The protein expression levels of LC3BI, LC3BII and Beclin-1 were detected in the H/R model cells using western blotting. LC3BII/LC3BI ratio and Beclin-1 protein levels 
A
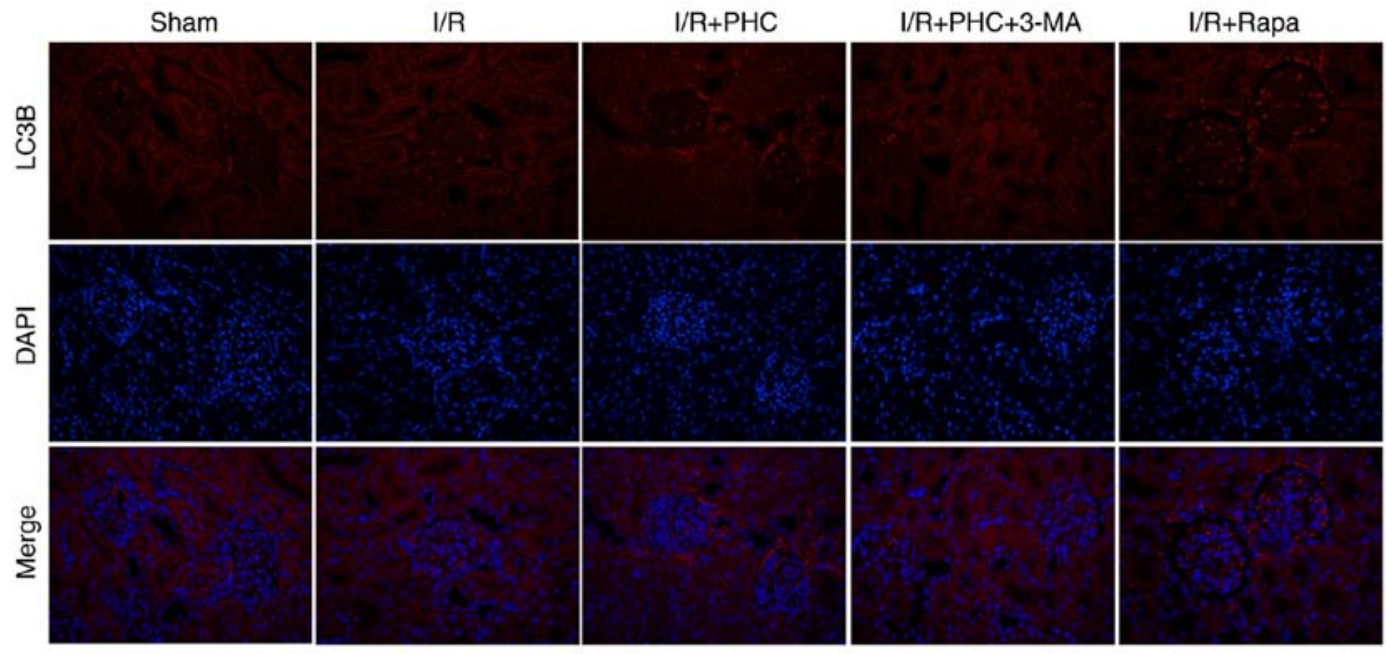

B
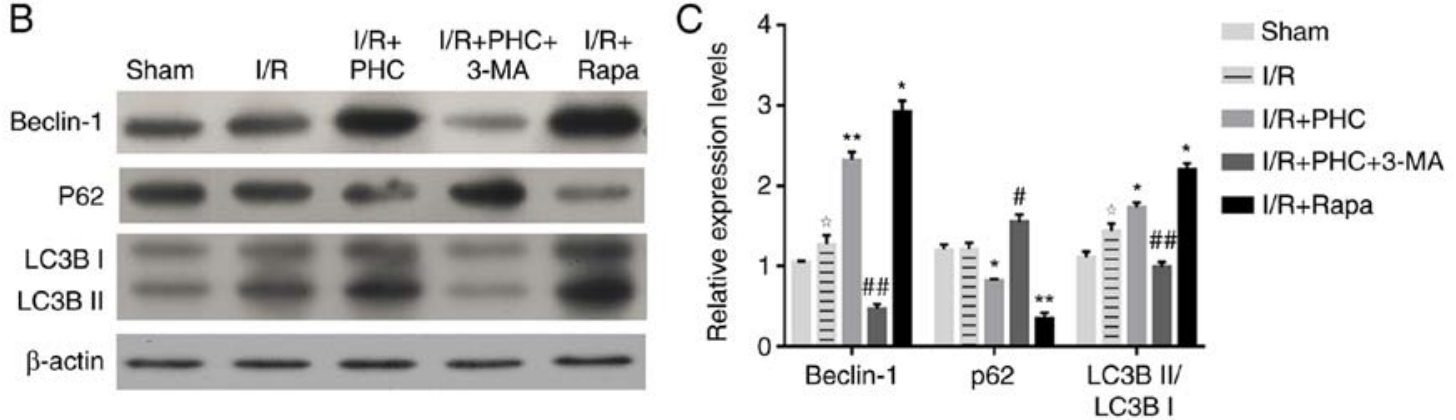

Figure 3. PHC promotes autophagic processes during inhibition of renal IRI. (A) Immunofluorescence micrographs of LC3B protein expression levels in IRI model rats following treatment with PHC, 3-MA or Rapa. Magnification, x100. (B) Expression levels of Beclin-1, p62 and LC3B in the renal tissues of IRI model rats following treatment with PHC, 3-MA or Rapa, as determined by western blotting. $\beta$-actin served as the internal loading control. (C) Semi-quantitative analysis of relative expression levels of Beclin-1, p62 and LC3B analyzed in (B). Fold change to $\beta$-actin expression is presented. ${ }^{2} \mathrm{P}<0.05$ vs. sham group; ${ }^{*} \mathrm{P}<0.05$ and ${ }^{* *} \mathrm{P}<0.01$ vs. I/R group; ${ }^{\#} \mathrm{P}<0.05$ and ${ }^{\# \#} \mathrm{P}<0.01$ vs. I/R + PHC group. $3-\mathrm{MA}, 3-$ methyladenine; I/R, ischemia/reperfusion; IRI, I/R injury; LC3B, microtubule-associated protein light chain 3B; p62, sequestome 1; PHC, penehyclidine hydrochloride; Rapa, rapamycin.

were significantly increased in the $\mathrm{H} / \mathrm{R}+\mathrm{PHC}$ and $\mathrm{H} / \mathrm{R}$ + Rapa groups compared with the H/R group; however, expression levels were significantly decreased in the $H / R$ $+\mathrm{PHC}+3$-MA group compared with the H/R + PHC group (Fig. 4B and C). p62 expression levels demonstrated significant changes that were opposite to the changes in the observed expression levels of LCB and Beclin-1; p62 expression levels were significantly decreased by PHC or Rapa treatment compared with $\mathrm{H} / \mathrm{R}$ cells, but were significantly increased in the $\mathrm{H} / \mathrm{R}+\mathrm{PHC}+3-\mathrm{MA}$ group compared with the $\mathrm{H} / \mathrm{R}+\mathrm{PHC}$ group (Fig. 4B and C).

TEM revealed that PHC or Rapa treatment $(\mathrm{H} / \mathrm{R}+\mathrm{PHC}$ and H/R + Rapa groups, respectively) promoted autophagosome formation in the cellular H/R model; however, PHC-induced autophagy in the HK-2 H/R model was prevented by 3-MA treatment $(\mathrm{H} / \mathrm{R}+\mathrm{PHC}+3-\mathrm{MA}$ group; Fig. 4D). Notably, immunofluorescence studies demonstrated that LC3B expression levels were increased in the $H / R+$ PHC group and were markedly decreased in the H/R + PHC + 3-MA group (Fig. 4E). Furthermore, Rapa treatment markedly increased LC3B expression levels in the H/R + Rapa group (Fig. 4E). These assays conducted on the in vitro $\mathrm{H} / \mathrm{R}$ model suggested that PHC treatment may promote renal cell proliferation during IRI through the activation of autophagic processes.
Autophagy mediates PHC-induced inhibition of apoptosis in the in vitro $H / R$ model. To further investigate the underlying cellular mechanisms, the apoptotic rate of H/R model cells treated with PHC was investigated. Flow cytometric analysis and Hoechst staining revealed a significantly increased number of apoptotic HK-2 cells in the H/R group compared with the control group (Fig. 5A-C). Treatment with PHC or Rapa (H/R + PHC and $\mathrm{H} / \mathrm{R}+$ Rapa groups, respectively) significantly decreased the rate of cell apoptosis compared with the H/R group; however, the decrease in apoptosis caused by PHC was ameliorated by treatment with 3-MA, with the H/R + PHC + 3-MA group demonstrating significantly enhanced levels of apoptosis compared with the H/R + PHC group (Fig. 5A-C). In terms of molecular pathways, Bcl-2 expression levels were significantly decreased in the H/R group compared with the control group (Fig. 5D and E). Treatment with PHC or Rapa significantly increased Bcl-2 expression levels compared with the H/R group, whereas 3-MA treatment significantly reduced the increase in Bcl-2 expression levels induced by PHC (Fig. 5D and E). The protein expression levels of Bax and caspase -3 in the $H / R$ group exhibited opposite trends to those exhibited by $\mathrm{Bcl}-2$; Bax and caspase-3 protein expression levels were increased by $\mathrm{H} / \mathrm{R}$ and 3-MA treatment, but decreased by PHC or Rapa treatment (Fig. 5D and E). Taken together, these data suggested that PHC may suppress the 
A

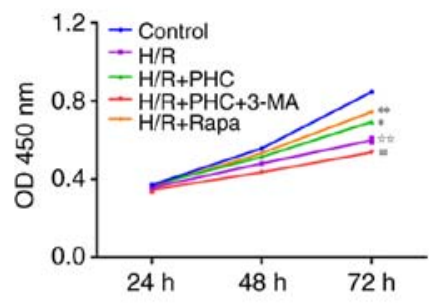

B

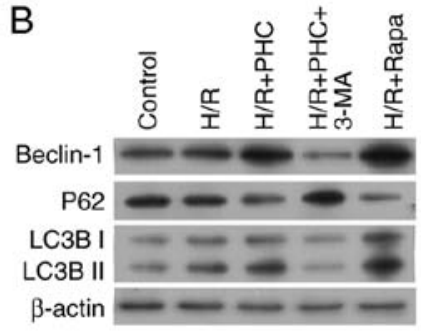

C

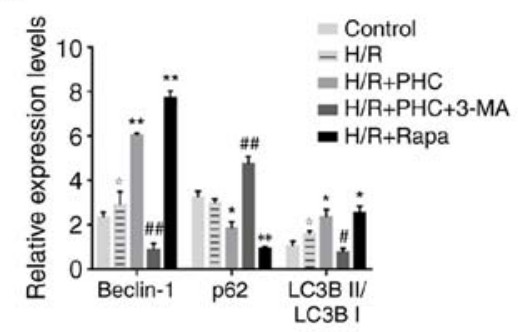

D

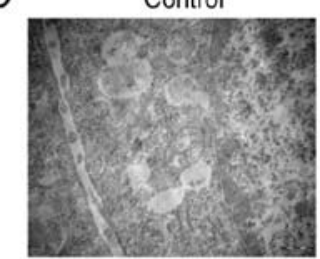

E

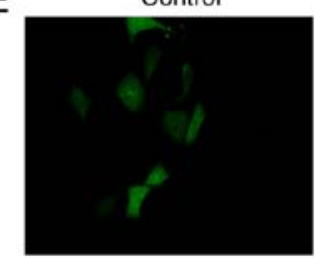

$\mathrm{H} / \mathrm{R}$

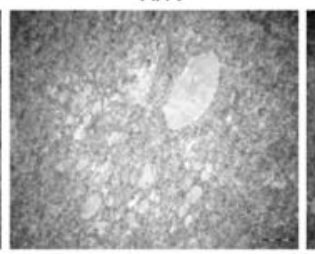

$\mathrm{H} / \mathrm{R}$

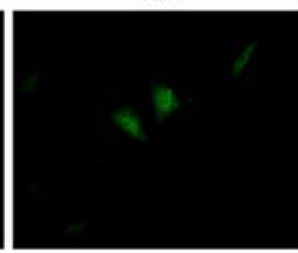

$\mathrm{H} / \mathrm{R}+\mathrm{PHC}$

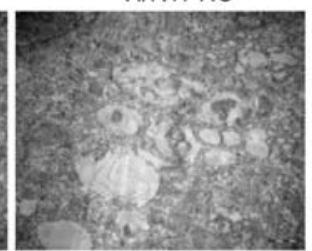

$\mathrm{H} / \mathrm{R}+\mathrm{PHC}$

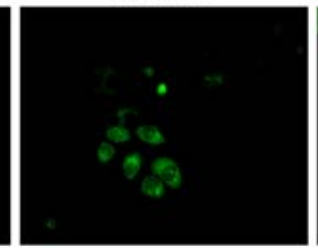

$\mathrm{H} / \mathrm{R}+\mathrm{PHC}+3-\mathrm{MA}$

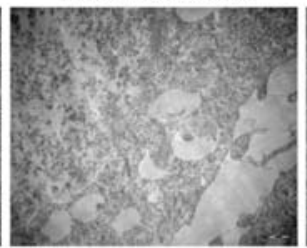

$\mathrm{H} / \mathrm{R}+\mathrm{PHC}+3-\mathrm{MA}$

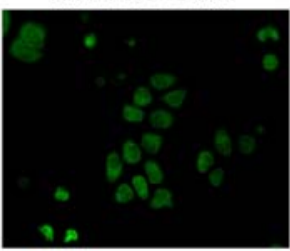

$\mathrm{H} / \mathrm{R}+\mathrm{Rapa}$

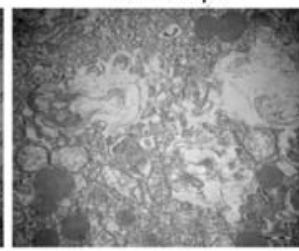

H/R+Rapa

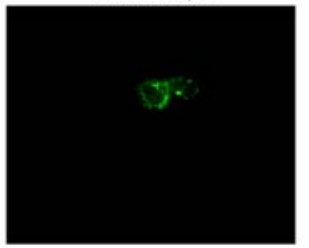

Figure 4. PHC promotes the proliferation of H/R model cells through activating autophagy. The cellular H/R model was established by treating human proximal tubular HK-2 cells with hypoxia, followed by reoxygenation. (A) Proliferation rates of human proximal tubular HK-2 cells following treatment with PHC, 3-MA or Rapa. Cell proliferation was determined using the Cell Counting kit-8 assay. (B) Expression levels of Beclin-1, p62 and LC3B in H/R model cells following treatment with PHC, 3-MA or Rapa. $\beta$-actin served as the internal loading control. (C) Semi-quantitative analysis of relative expression levels of Beclin-1, p62 and LC3B analyzed in (B). Fold change to $\beta$-actin expression is presented. (D) Evaluation of autophagosome formation in H/R model cells using transmission electron microscopy (magnification, $\mathrm{x} 200$ ). (E) LC3B expression levels in H/R model cells following treatment with PHC, 3-MA or Rapa (magnification, $\mathrm{x} 200$ ). ${ }^{*} \mathrm{P}<0.05$ and ${ }^{*} \mathrm{P}<0.01$ vs. control group; ${ }^{*} \mathrm{P}<0.05$ and ${ }^{* *} \mathrm{P}<0.01$ vs. $\mathrm{H} / \mathrm{R}$ group; ${ }^{\text {\# }} \mathrm{P}<0.05$ and ${ }^{\# \prime \prime} \mathrm{P}<0.01$ vs. $\mathrm{H} / \mathrm{R}+\mathrm{PHC}$ group. 3-MA, 3-methyladenine; H/R, hypoxia and reoxygenation; LC3B, microtubule-associated protein light chain 3B; OD, optical density; p62, sequestome 1; PHC, penehyclidine hydrochloride; Rapa, rapamycin.

apoptosis of renal cells induced by $H / R$ through promoting autophagy.

\section{Discussion}

Autophagy is an important cellular event that protects against various tissue injuries induced by I/R; significantly increased numbers of autophagosomes, the key intracellular structures in autophagy, have been observed in the tubular cells of I/R model mice, as well as in tissue specimens collected from patients with transplanted kidneys (39). Jiang et al (25) observed that the inhibition of autophagy led to increased numbers of apoptotic renal cells and autophagy inhibition in I/R model mice, which promoted more severe renal injuries, suggesting that autophagy may serve as a protective mechanism for renal cell survival during IRI (25). When monitoring autophagy and apoptosis in I/R model mice for a period of 0 to 7 days post-reperfusion, autophagy was induced in a time-dependent manner and earlier than cell apoptosis (24). Considering the significance of autophagy in the pathogenesis of renal IRI, the potential pharmacological effects of autophagy during PHC-induced renal IRI inhibition was investigated. Treatment with PHC or the autophagy inducer Rapa effectively suppressed renal tissue damage in rats in the I/R group, whereas treatment with the autophagy inhibitor 3-MA greatly reduced the inhibitory effect of PHC. These results suggested a critical role for autophagy during PHC-induced suppression of renal IRI. Rapa is an inhibitor of mTOR that can be activated by hypoxia or ROS directly or indirectly through the activation of AKT signaling (40-43). The activation of mTOR inhibits the expression of ATGs and the formation of autophagosomes $(40,41)$; hypoxia-induced autophagy has been reported in IRI $(42,43)$. Wang et al (17) demonstrated that PHC significantly suppressed renal IRI through suppressing MAPK, caspase-3 and NF- $\kappa \mathrm{B}$ protein activity.

The present study demonstrated that autophagy processes were enhanced in renal tissue following IRI. The microtubule-associated protein LC3B is a central coordinator in the autophagy pathway and it is responsible for autophagy substrate selection and autophagosome biogenesis (Fig. 6) (30); it is widely used as a protein marker of autophagosome formation. The present study demonstrated that PHC treatment significantly increased LC3BII expression levels in the IRI model rats and in vitro $\mathrm{H} / \mathrm{R}$ model, suggesting that $\mathrm{PHC}$ may induce autophagy. Beclin-1, as the mammalian orthologue of yeast ATG6, promotes autophagy and programmed cell survival through interacting with various cofactors, such as ATG14 and survivin proteins (32). Loss of function mutations or polymorphisms of autophagy genes, such as autophagy-related 16-like 1, ATG5 and immunity-related GTPase family M disrupt cellular autophagy processes and induce cellular injury, and are therefore relevant to many chronic inflammatory 


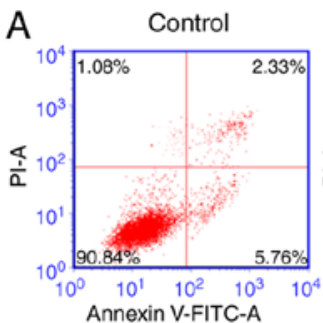

B
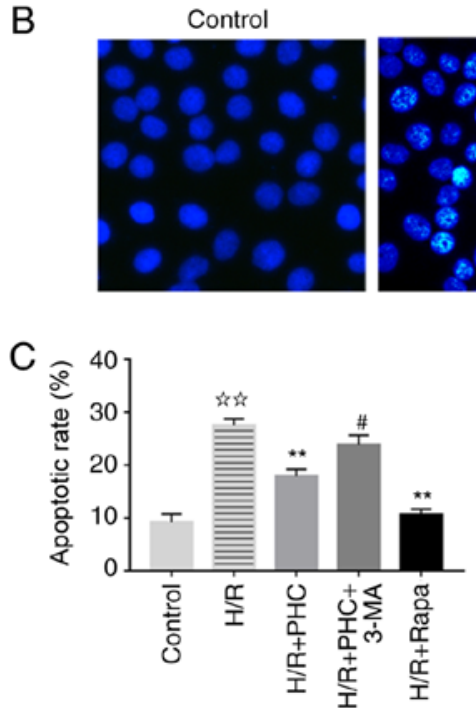

$\mathrm{H} / \mathrm{R}$

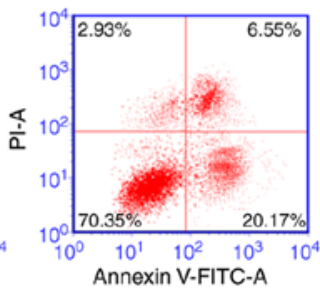

$\mathrm{H} / \mathrm{R}$

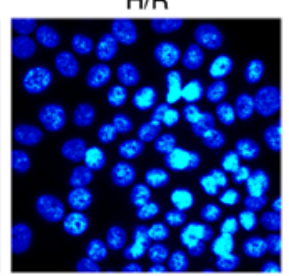

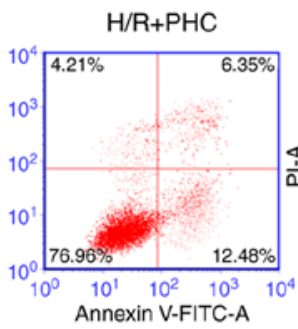

$\mathrm{H} / \mathrm{R}+\mathrm{PHC}$

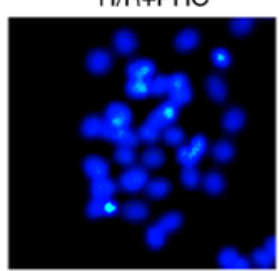

D

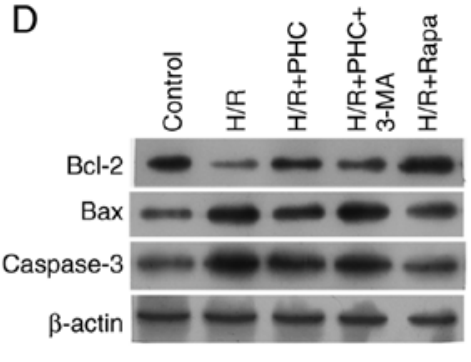

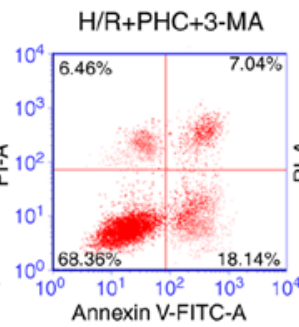

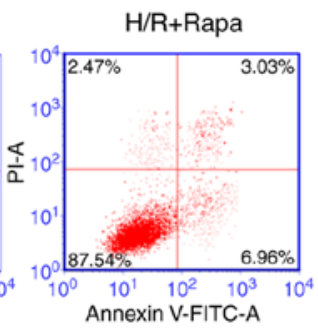

$\mathrm{H} / \mathrm{R}+\mathrm{PHC}+3-\mathrm{MA}$
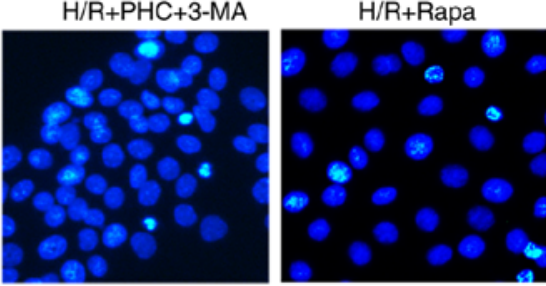

$\mathrm{E}$

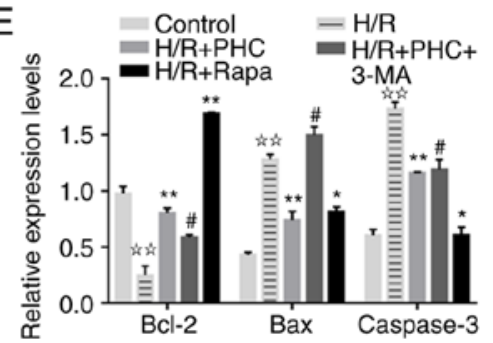

Figure 5. PHC suppresses the apoptosis of H/R model cells through activating autophagy. The cellular H/R model was established by hypoxia and subsequent reoxygenation. (A) Flow cytometric analysis of apoptosis in the cellular H/R model following treatment with PHC, 3-MA or Rapa. (B) Analysis of apoptosis in the cellular H/R model following treatment with PHC, 3-MA or Rapa using Hoechst 33258 staining (magnification, $\mathrm{x} 400$ ). (C) Semi-quantitative analysis of apoptosis analyzed in (A). (D) Expression levels of Bcl-2, Bax and caspase-3 in the cellular H/R model following treatment with PHC, 3-MA or Rapa using western blotting. (E) Semi-quantitative analysis of Bcl-2, Bax and caspase-3 expression levels from (D). Fold change to $\beta$-actin expression is presented. ${ }^{2} \mathrm{P}<0.01$ vs. control group; ${ }^{*} \mathrm{P}<0.05$ and ${ }^{* *} \mathrm{P}<0.01$ vs. H/R group; ${ }^{*} \mathrm{P}<0.05$ vs. $\mathrm{H} / \mathrm{R}+\mathrm{PHC}$ group. 3-MA, 3-methyladenine; H/R, hypoxia and reoxygenation; PHC, penehyclidine hydrochloride; PI, propidium iodide; Rapa, rapamycin.

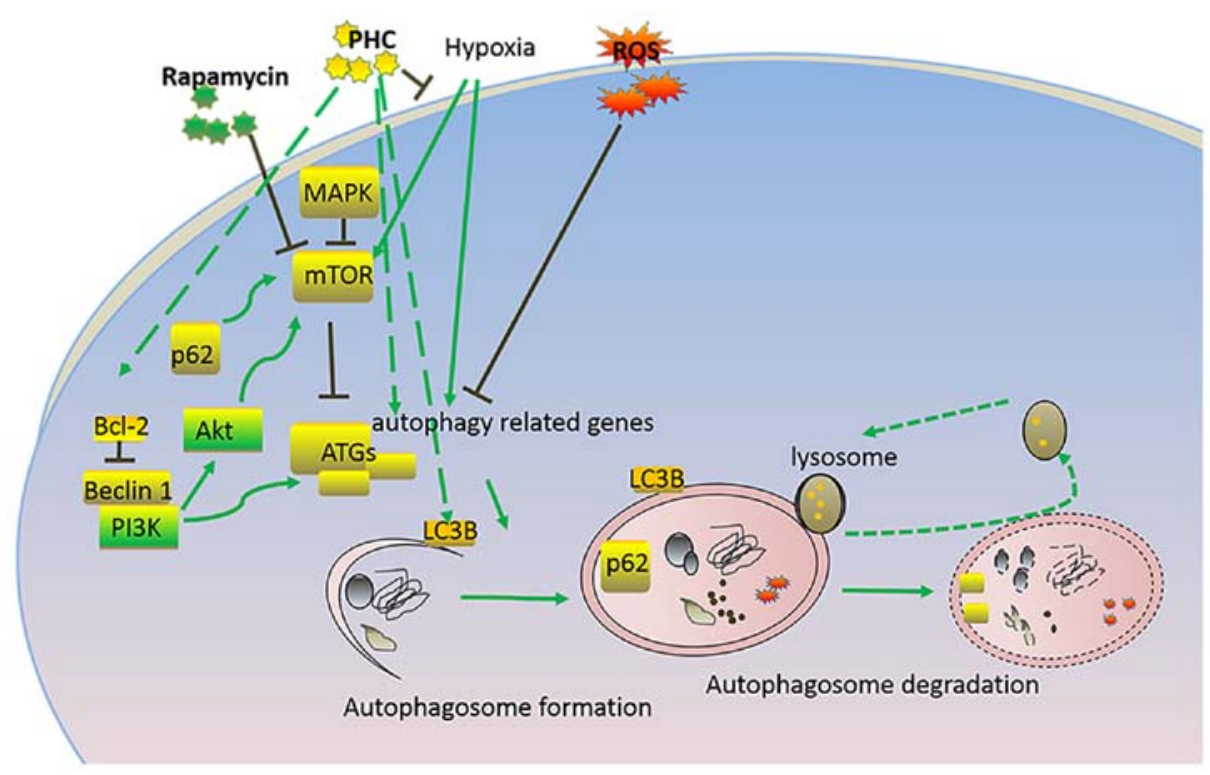

Figure 6. Proposed mechanism of action mediated by PHC-induced suppression of renal IRI. PHC promotes IRI-induced autophagy by inhibiting hypoxia-induced mTOR activation of LC3B and thereby promotes autophagosome formation. ATG, autophagy-related genes; IRI, ischemia/reperfusion injury; LC3B; microtubule-associated protein light chain 3B; MAPK, mitogen activated protein kinase; p62, sequestome 1; mTOR, mammalian target of rapamycin; PHC, penehyclidine hydrochloride; ROS, reactive oxygen species.

diseases (44-47). PHC treatment also significantly increased Beclin-1 expression levels in the in vivo and in vitro models of renal IRI, whereas the adaptor protein p62 demonstrated opposite trends in expression levels compared with Beclin-1 
expression. p62 was initially identified as an interacting partner of atypical protein kinase $\mathrm{C}$, and is associated with both cell apoptosis and autophagy processes (33). The negative regulation or elimination of p62 expression by autophagy has been demonstrated to be an important mechanism of tumorigenesis and other biological processes $(33,48)$. In the present study, it was observed that p62 protein expression levels were significantly suppressed by PHC treatment and autophagy, providing further evidence that PHC may induce autophagy in renal cells during IRI. The involvement of autophagy in PHC-induced inhibition of renal IRI in this study is consistent with other studies, which reported that the activation of autophagy protected against tissue damage under various conditions (49-51), and further highlights the significance of autophagy in suppressing tissue damage.

Suppressed cell proliferation has been frequently observed during renal IRI and the promotion of tubular cell proliferation is the natural response during recovery from renal dysfunction $(52,53)$; for example, the transcription factor transcriptional repressor GATA-binding 1, which was initially characterized as an essential regulator of cell morphogenesis during kidney development, promoted tubular cell proliferation following IRI through regulating cyclic AMP-specific 3',5'-cyclic phosphodiesterase activity and AKT signaling, and it is thus viewed as a potential target for treating kidney IRI (53). In the present study, it was demonstrated that PHC treatment significantly promoted renal cell proliferation, alongside increasing Bcl-2 expression levels (Fig. 6), which suggested the importance of tubular cell regulation during an $\mathrm{I} / \mathrm{R}$-induced renal tissue injury. It was also observed that the autophagy inhibitor 3-MA inhibited PHC-induced renal cell proliferation, which further indicated the mediating role that PHC-induced activation of autophagy may serve in renal cell proliferation. These findings suggested that other autophagy and proliferation-promoting reagents may be used as therapeutic treatments for IRIs.

Autophagy is viewed as a process of programmed cell survival, which may counteract apoptosis through mediating interactions among Bcl-2, caspases and Beclin-1 proteins (Fig. 6) (33). The present study demonstrated that PHC treatment significantly suppressed the apoptosis of renal cells during I/R and this effect was attributed to PHC-induced autophagy activation. The suppression of apoptosis by PHC-induced autophagy was also supported through the decreased expression levels of Bax and caspase-3, which are two major apoptosis-promoting proteins (54), as well as through the increased expression levels of Bcl-2 protein, which is a key pro-survival factor associated with cell apoptosis regulation (55). The regulation of cell proliferation and apoptosis by autophagy has been demonstrated in various biological and pathogenic processes, such as hepatocarcinoma development (56). By observing the synergistic modulation of renal cell proliferation and apoptosis through PHC-induced autophagy activation, the present study has contributed to the further understanding of renal IRI pathogenesis and treatment. Thus, the interactions between changes in cell apoptosis and proliferation levels associated with tissue injuries of other origins, as well as their involvement in treatment with other therapeutic reagents, requires further investigation.

In conclusion, it is well known that autophagy is mediated by mTOR-regulated activation of ATGs, which further promote LC3B activation and autophagy progression, and autophagy could also be regulated by Bcl-2, Beclin-1 and p62 (Fig. 6). Our present study demonstrated that PHC may suppress renal IRI through inducing autophagy in an in vivo rat model and an in vitro cellular model; this effect was mediated through enhanced renal cell proliferation and suppressed renal cell apoptosis. These findings may provide novel insight into the therapeutic effects of PHC on renal IRI treatment, and may also provide a basis for developing novel anti-IRI drugs.

\section{Acknowledgements}

Not applicable.

\section{Funding}

This study was supported by The Jinshan District of Shanghai Science and Technology Innovation Fund Project: The Program of Effect of Penehyclidine Hydrochloride on Renal Autophagy in Ischemia-reperfusion Rats (grant no. 2016-3-08).

\section{Availability of data and materials}

All data generated or analyzed during this study are included in this published article.

\section{Authors' contributions}

JuZ conceived and designed the project. YK, YL, HW, JiZ and ZF performed the experiments. YK and HW analyzed and interpreted the data. YK and YL wrote the paper.

\section{Ethics approval and consent to participate}

All procedures in this study were approved by The Ethics Committee for Experimental Animals of the Jinshan Branch Hospital of Shanghai Sixth People's Hospital and were carried out in strict accordance with The Guidelines for the Care and Use of Laboratory Animals (National Institutes of Health).

\section{Patient consent for publication}

Not applicable.

\section{Competing interests}

The authors declare that they have no competing interests.

\section{References}

1. Malek M and Nematbakhsh M: Renal ischemia/reperfusion injury; from pathophysiology to treatment. J Renal Inj Prev 4: 20-27, 2015.

2. Sharfuddin AA and Molitoris BA: Pathophysiology of ischemic acute kidney injury. Nat Rev Nephrol 7: 189-200, 2011.

3. Danobeitia JS, Djamali A and Fernandez LA: The role of complement in the pathogenesis of renal ischemia-reperfusion injury and fibrosis. Fibrogenesis Tissue Repair 7: 16, 2014.

4. Kellum JA, Unruh ML and Murugan R: Acute kidney injury. BMJ Clin Evid 2011: pii: 2001, 2011.

5. Ling H, Chen H, Wei M, Meng X, Yu Y and Xie K: The effect of autophagy on inflammation cytokines in renal ischemia/reperfusion injury. Inflammation 39: 347-356, 2016. 
6. Liu D, Shang H and Liu Y: Stanniocalcin-1 protects a mouse model from renal ischemia-reperfusion injury by affecting ROS-mediated multiple signaling pathways. Int J Mol Sci 17: pii: E1051, 2016.

7. Wen J, Shu Y and Zhang W: ROS, P53, and ischemic acute kidney injury in diabetic models. Kidney Int 88: 198-199, 2015.

8. Qiao X, Chen X, Wu D, Ding R, Wang J, Hong Q, Shi S, Li J, Xie Y, Lu Y and Wang Z: Mitochondrial pathway is responsible for aging-related increase of tubular cell apoptosis in rena ischemia/reperfusion injury. J Gerontol A Biol Sci Med Sci 60 830-839, 2005

9. Migita H, Yoshitake S, Tange Y, Choijookhuu N and Hishikawa Y: Hyperbaric oxygen therapy suppresses apoptosis and promotes renal tubular regeneration after renal ischemia/reperfusion injury in rats. Nephrourol Mon 8: e34421, 2016.

10. Jie L, Hong Z, Hong L, Zhou J, Cui L, Yuan S, Chu X and Yu P. Hydrogen-rich saline promotes the recovery of renal function after ischemia/reperfusion injury in rats via anti-apoptosis and anti-inflammation. Front Pharmacol 7: 106, 2016.

11. Zhang Y, Fu Z, Zhong Z, Wang R, Hu L, Xiong Y, Wang Y and Ye Q: Hypothermic machine perfusion decreases renal cell apoptosis during ischemia/reperfusion injury via the Ezrin/AKT pathway. Artif Organs 40: 129-135, 2016.

12. Yu C and Wang J: Neuroprotective effect of penehyclidine hydrochloride on focal cerebral ischemiareperfusion injury. Neural Regen Res 8: 622-632, 2013.

13. Shen W, Gan J, Xu S, Jiang G and Wu H: Penehyclidine hydrochloride attenuates LPS-induced acute lung injury involvement of NF-kappaB pathway. Pharmacol Res 60: 296-302, 2009.

14. Zhan J, Liu Y, Zhang Z, Chen C, Chen K and Wang Y: Effect of penehyclidine hydrochloride on expressions of MAPK in mice with CLP-induced acute lung injury. Mol Biol Rep 38: 1909-1914, 2011.

15. Cai DS, Jin BB, Pei L and Jin Z: Protective effects of penehyclidine hydrochloride on liver injury in a rat cardiopulmonary bypass model. Eur J Anaesthesiol 27: 824-828, 2010.

16. Zhang Y, Leng YF, Xue X, Zhang Y, Wang T and Kang YQ: Effects of penehyclidine hydrochloride in small intestinal damage caused by limb ischemia-reperfusion. World J Gastroenterol 17: 254-259, 2011

17. Wang YP, Li G, Ma LL, Zheng Y, Zhang SD, Zhang HX, Qiu M and Ma X: Penehyclidine hydrochloride ameliorates renal ischemia-reperfusion injury in rats. J Surg Res 186: 390-397, 2014.

18. Mizushima N and Komatsu M: Autophagy: Renovation of cells and tissues. Cell 147: 728-741, 2011

19. Caramés B, Taniguchi N, Otsuki S, Blanco FJ and Lotz M Autophagy is a protective mechanism in normal cartilage, and its aging-related loss is linked with cell death and osteoarthritis. Arthritis Rheum 62: 791-801, 2010.

20. Cursio R, Colosetti P and Gugenheim J: Autophagy and liver ischemia-reperfusion injury. Biomed Res Int 2015: 417590, 2015.

21. Cardinal J, Pan P and Tsung A: Protective role of cisplatin in ischemic liver injury through induction of autophagy. Autophagy 5 : $1211-1212,2009$

22. Lu Y, Wang WJ, Song YZ and Liang ZQ: The protective mechanism of schisandrin $\mathrm{A}$ in d-galactosamine-induced acute liver injury through activation of autophagy. Pharm Biol 52: 1302-1307, 2014

23. Wang D, Ma Y, Li Z, Kang K, Sun X, Pan S, Wang J, Pan H, Liu L, Liang D and Jiang H: The role of AKT1 and autophagy in the protective effect of hydrogen sulphide against hepatic ischemia/reperfusion injury in mice. Autophagy 8: 954-962, 2012.

24. Guan X, Qian Y, Shen Y, Zhang L, Du Y, Dai H, Qian J and Yan Y: Autophagy protects renal tubular cells against ischemia/reperfusion injury in a time-dependent manner. Cell Physiol Biochem 36: 285-298, 2015.

25. Jiang M, Liu K, Luo J and Dong Z: Autophagy is a renoprotective mechanism during in vitro hypoxia and in vivo ischemia-reperfusion injury. Am J Pathol 176: 1181-1192, 2010

26. Weisman R: Target of rapamycin (TOR) regulates growth in response to nutritional signals. Microbiol Spectr 4, 2016.

27. Yang $\mathrm{Z}$ and Klionsky DJ: Mammalian autophagy: Core molecular machinery and signaling regulation. Curr Opin Cell Biol 22: 124-131, 2010

28. Cao QH, Liu F, Yang ZL, Fu XH, Yang ZH, Liu Q, Wang L, Wan XB and Fan XJ: Prognostic value of autophagy related proteins ULK1, Beclin 1, ATG3, ATG5, ATG7, ATG9, ATG10, ATG12, LC3B and p62/SQSTM1 in gastric cancer. Am J Transl Res 8: 3831-3847, 2016.
29. Hamacher-Brady A: Autophagy regulation and integration with cell signaling. Antioxid Redox Signal 17: 756-765, 2012.

30. Abeliovich $\mathrm{H}$ : Guidelines for the use and interpretation of assays for monitoring autophagy. Haematologica 27: 151-175, 2012.

31. Tiwari RV, Parajuli P and Sylvester PW: Synergistic anticancer effects of combined $\gamma$-tocotrienol and oridonin treatment is associated with the induction of autophagy. Mol Cell Biochem 408: 123-137, 2015.

32. Kang R, Zeh HJ, Lotze MT and Tang D: The Beclin 1 network regulates autophagy and apoptosis. Cell Death Differ 18: 571-580, 2011.

33. Moscat J and Diaz-Meco MT: p62 at the crossroads of autophagy, apoptosis, and cancer. Cell 137: 1001-1004, 2009.

34. National Research Council (US) Committee for the Update of the Guide for the Care and Use of Laboratory Animals: Guide for the Care and Use of Laboratory Animals, 8th edition. National Academies Press (US), Washington (DC), 2011.

35. Zheng Y, Lu M, Ma L, Zhang S, Qiu M and Wang Y: Osthole ameliorates renal ischemia-reperfusion injury in rats. J Surg Res 183: 347-354, 2013

36. Shimizu S, Saito M, Kinoshita Y, Ohmasa F, Dimitriadis F, Shomori K, Hayashi A and Satoh K: Nicorandil ameliorates ischaemia-reperfusion injury in the rat kidney. Br J Pharmacol 163: 272-282, 2011

37. Jia X, Zhang L and Mao X: S-propranolol protected H9C2 cells from ischemia/reperfusion-induced apoptosis via downregultion of RACK1 gene. Int J Clin Exp Pathol 8: 10335-10344, 2015.

38. Swanlund JM, Kregel KC and Oberley TD: Investigating autophagy: Quantitative morphometric analysis using electron microscopy. Autophagy 6: 270-277, 2010.

39. Suzuki C, Isaka Y, Takabatake Y, Tanaka H, Koike M, Shibata M, Uchiyama Y, Takahara S and Imai E: Participation of autophagy in renal ischemia/reperfusion injury. Biochem Biophys Res Commun 368: 100-106, 2008

40. Wu ZZ, Zhang JJ, Gao CC, Zhao M, Liu SY, Gao GM and Zheng ZH: Expression of autophagy related genes mTOR, Becline-1,LC3 and p62 in the peripheral blood mononuclear cells of systemic lupus erythematosus. Am J Clin Exp Immunol 6: 1-8, 2017.

41. Cerni S, Shafer D, To K and Venketaraman V: Investigating the role of everolimus in mTOR inhibition and autophagy promotion as a potential host-directed therapeutic target in mycobacterium tuberculosis infection. J Clin Med 8: pii: E232, 2019.

42. Rouschop K and Wouters BG: Regulation of autophagy through multiple independent hypoxic signaling pathways. Curr Mol Med 9: 417-424, 2009.

43. Ma S, Wang Y, Chen Y and Cao F: The role of the autophagy in myocardial ischemia/reperfusion injury. Biochim Biophys Acta 1852: 271-276, 2015

44. Nuij VJAA, Peppelenbosch MP, van der Woude CJ and Fuhler GM: Genetic polymorphism in ATG16L1 gene is associated with adalimumab use in inflammatory bowel disease. J Transl Med 15: 248, 2017.

45. Cucu MG, Streața I, Riza AL and Lilin A: Polymorphisms in autophagy genes and active pulmonary tuberculosis susceptibility in Romania. Rev Romana Med Lab 25: 47-53, 2017.

46. Kabat AM, Harrison OJ, Riffelmacher T, Moghaddam AE, Pearson CF, Laing A, Abeler-Dörner L, Forman SP, Grencis RK, Sattentau Q, et al: The autophagy gene Atg1611 differentially regulates Treg and $\mathrm{TH} 2$ cells to control intestinal inflammation. Elife 5: e12444, 2016.

47. Lin YC, Chang PF, Lin HF, Liu K, Chang MH and Ni YH: Variants in the autophagy-related gene IRGM confer susceptibility to non-alcoholic fatty liver disease by modulating lipophagy. J Hepatol 65: 1209-1216, 2016.

48. Mathew R, Karp CM, Beaudoin B, Vuong N, Chen G, Chen HY, Bray K, Reddy A, Bhanot G, Gelinas C, et al: Autophagy suppresses tumorigenesis through elimination of p62. Cell 137: 1062-1075, 2009

49. Pu D, Lianos EA, Ma J and Lin PH: Autophagy, innate immunity and tissue repair in acute kidney injury. Int J Mol Sci 17: pii: E662, 2016.

50. Mukhopadhyay P, Eid N, Abdelmegeed MA and Sen A: Interplay of oxidative stress, inflammation, and autophagy: Their role in tissue injury of the heart, liver, and kidney. Oxid Med Cell Longev 2018: 2090813, 2018.

51. Sekiguchi A, Kanno H, Ozawa H, Yamaya S and Itoi E: Rapamycin promotes autophagy and reduces neural tissue damage and locomotor impairment after spinal cord injury in mice. J Neurotrauma 29: 946-956, 2012. 
52. Nguan CYC, Guan Q, Gleave ME and Du C: Promotion of cell proliferation by clusterin in the renal tissue repair phase after ischemia-reperfusion injury. Am J Physiol Renal Physiol 306: F724-F733, 2014.

53. Ju-Rong Y, Ke-Hong C, Kun H, Bi-Qiong F, Li-Rong L, Jian-Guo Z, Kai-Long L and Ya-Ni H: Transcription factor Trps1 promotes tubular cell proliferation after ischemia-reperfusion injury through cAMP-specific 3',5'-cyclic phosphodiesterase 4D and AKT. J Am Soc Nephrol 28: 532-544, 2017.

54. Peiró G, Diebold J, Baretton GB, Kimmig R and Löhrs U: Cellular apoptosis susceptibility gene expression in endometrial carcinoma: Correlation with Bcl-2, Bax, and caspase-3 expression and outcome. Int J Gynecol Pathol 20: 359-367, 2001.
55. Adams JM and Cory S: The Bcl-2 apoptotic switch in cancer development and therapy. Oncogene 26: 1324-1337, 2007.

56. Guo XL, Li D, Hu F, Song JR, Zhang SS, Deng WJ, Sun K, Zhao QD, Xie XQ, Song YJ, et al: Targeting autophagy potentiates chemotherapy-induced apoptosis and proliferation inhibition in hepatocarcinoma cells. Cancer Lett 320: 171-179, 2012.

This work is licensed under a Creative Commons Attribution-NonCommercial-NoDerivatives 4.0 International (CC BY-NC-ND 4.0) License. 